\title{
Breves apontamentos sobre a fraude no processo e no direito material
}

\author{
Brief notes about fraud in the process and in material law \\ Breve notas sobre el fraude en el proceso y en el derecho material
}

Recebido: 07/02/2022 | Revisado: 14/02/2022 | Aceito: 19/02/2022 | Publicado: 01/03/2022

\author{
Paulo Gustavo Trento \\ ORCID: https://orcid.org/0000-0001-6957-2275 \\ Universidade Paranaense, Brasil \\ E-mail: paulogustavotrento@gmail.com
}

\begin{abstract}
Resumo
O objetivo desse trabalho é abordar a respeito da fraude no âmbito do direito brasileiro. Para o estudo, é necessário que se proceda com a devida distinção do que se classifica como fraude no âmbito do direito processual, ou seja, fraude no processo, bem como, o que é considerado e classificado como fraude no direito material, ligada diretamente à obrigações regidas pela legislação civil. É importante que se faça tal definição a fim de que seja possível, no âmbito do debate jurídico, definir a norma aplicável e a forma de proceder, se a fraude vislumbrada se tratar de fraude processual ou material, compreendendo que essa classificação dirá se a fraude é contra a execução ou contra credores, importante diferenciação para o tratamento jurídico. Reconhecer a fraude e a sua classificação do meio jurídico é necessário para que seja possível repreender o ato ilícito e desfazer operações que visam burlar a lei e prejudicar legítimos credores, através de incisiva atuação do Poder Judiciário.
\end{abstract}

Palavras-chave: Fraude processual ou material; Direito processual; Direito material.

\begin{abstract}
The objective of this work is to approach about fraud in the scope of Brazilian law. For the study, it is necessary to proceed with the due distinction of what is classified as fraud in the scope of procedural law, that is, fraud in the process, as well as, what is considered and classified as fraud in substantive law, directly linked to the obligations governed by civil law. It is important that such a definition is made so that it is possible, within the scope of the legal debate, to define the applicable rule and the way to proceed, if the fraud envisaged is procedural or material fraud, understanding that this classification will determine whether the fraud is against execution or against creditors, an important differentiation for legal treatment. Recognizing fraud and its classification in the legal environment is necessary so that it is possible to reprimand the illicit act and undo operations that aim to circumvent the law and harm legitimate creditors, through incisive action by the Judiciary.
\end{abstract}

Keywords: Procedural or material fraud; Procedural law; Substantive law.

\begin{abstract}
o
El objetivo de este trabajo es abordar el tema del fraude en el ámbito del derecho brasileño. Para el estudio, es necesario proceder a la debida distinción de lo que se tipifica como dolo en el ámbito del derecho procesal, esto es, dolo en el proceso, así como, lo que se considera y tipifica como dolo en el derecho sustantivo, directamente vinculados a las obligaciones regidas por el derecho civil. Es importante que se haga tal definición para que sea posible, en el ámbito del debate jurídico, definir la regla aplicable y la forma de proceder, si el fraude previsto es procesal o material, entendiendo que esta calificación determinará si el fraude es contra la ejecución o contra los acreedores, una diferenciación importante para el tratamiento legal. El reconocimiento del fraude y su tipificación en el ámbito legal es necesario para que sea posible reprender el hecho ilícito y deshacer operaciones que tengan por objeto eludir la ley y perjudicar a los legítimos acreedores, mediante la acción incisiva del Poder Judicial.
\end{abstract}

Palabras clave: Fraude procesal o material; Derecho procesal; Derecho sustantivo. 


\section{Introdução}

O estudo da fraude no âmbito do direito processual e do direito material, com a devida distinção daquilo que é fraude em cada um desses ramos específicos e complementares do direito é importante para que tanto o legislador quanto o operador do direito possam saber como dirimir conflitos e aplicar a norma de forma contundente e eficaz para solução do litígio.

Desde sempre a sociedade é formada e sustentada pela relação mantida e existente entre todos, cada qual buscando dentro de seus limites e possibilidades, contribuir para o desenvolvimento social como um todo. Forma-se a todo momento novas relações entre pessoas, mas também entre pessoas fictícias, que se formam mediante a instituição de empresas, associações e instituições, por exemplo.

Esse desenvolvimento social e a modernização levou à criação da figura do crédito, fornecido mediante a cobrança de juros com o intuito de fomentar o investimento e o desenvolvimento social. Todavia, não raras as vezes aqueles que tomavam crédito não conseguiam adimplir com a obrigação assumida, mas também não admitiam ver os seus bens conquistados serem atingidos ou tomados pela dívida inadimplida, ou seja, agiam em fraude, mediante atos ilícitos.

O legislador então passou a se preocupar com meios de repressão ao ilícito, estabelecendo, por exemplo, a possibilidade de tornar ineficaz a operação de venda de bens, que se realizará com o intuito objetivo de tornar insolvente o devedor pela inexistência de bens que pudessem responder pela dívida.

\section{Metodologia}

No presente trabalho, utilizou-se de pesquisa bibliográfica, consistente na investigação de doutrina a respeito do tema, suas especificidades e também suas delimitações, a fim de apurar as diferenças entre o que se classifica como fraude no processo e fraude no direito material, e seus desdobramentos em fraude à execução e fraude contra credores. O objetivo aqui é uma contextualização sobre as principais abordagens teóricas e conceitos utilizados pela doutrina ao tratar do tema em debate, acerca da diferenciação daquilo que é fraude no processo e no direito material.

Fez-se, para tanto, pesquisa qualitativa, buscando compreender e interpretar os posicionamentos a respeito do tema e a complementação de cada posicionamento na formação de um conjunto de ideias para explanação sobre a matéria. Com isso, formulou-se a partir dos estudos bibliográficos realizados, uma abordagem acerca do conceito de fraude, ato contrário ao direito com objetivo de prejudicar credor, e o momento da sua prática visualizável, se no campo do processo, que se materializa quando praticada a partir da existência de uma demanda judicial com relação ao objeto ou instrumento fraudulento, ou até mesmo sua concretização no direito material, que se dá independentemente da existência de ação judicial em curso, bastando a existência de uma obrigação a ser honrada pelo credor, que tem por objetivo dilapidar-se e tornar-se inadimplente.

\section{Desenvolvimento}

A palavra fraude, deriva do latim fraus, significa uma ação contrária àquela que deveria ter sido realmente adotada, contrária ao que é correto e honesto. Refere-se a condutas adotadas com o objetivo de prejudicar uma pessoa ou uma organização, aqui compreendida com o Estado enquanto pessoa ou organização pública e empresas ou instituições de cunho privado.

Quando se fala em fraude como atitudes dotadas de intenção prejudicial contra outrem, é no intuito de prejudicar alguém mediante o não cumprimento de obrigações ordinariamente assumidas, bem como, usurpando qualquer possibilidade de este ver satisfeita a obrigação atingindo seu patrimônio.

Segundo Humberto Theodoro Junior (1996, p. 59): 
Quem cogita, portanto, de fraude no plano jurídico, pensa em astúcia ou malícia para lesar alguém, por meio de conduta desleal, mentirosa e injurídica. Contra este tipo de procedimento lesivo, a ordem jurídica se ergue, em todos os seus ramos, desde os do direito privado até os do direito público, seja na defesa de interesses puramente particulares, seja na repressão a prejuízos de interessa geral ou coletivo.

Nos dizeres de Cahali (1999, p. 50), o conceito de fraude reflete a má-fé, como negação expressa ao princípio da boafé. O princípio da boa-fé seria o caminho pela qual a moral penetra no direito.

A boa-fé é compreendida como sendo atos sólidos na conduta das partes, que devem agir com honestidade, correspondendo à confiança depositada pela outra parte, ou seja, é princípio a ser observado em todas as fazes inerentes à celebração de um negócio, a fim de que se estabelece uma relação de equilíbrio e saudável para a celebração de um contrato. (Pedrosa, 2013).

Judith Martins-Costa (2000, p. 411) é direta a conceituar a boa-fé como "modelo de conduta social, arquétipo ou standart jurídico, segundo o qual cada pessoa deve ajustar a propria conduta a esse arquétipo, obrando como obraria um homem reto: com honestidade, lealdade e probidade."

E, a boa-fé, enquanto princípio, nos dizeres de Ávila (2015, p. 104) estabelece "o dever de adotar comportamentos necessários à realização de um estado de coisas ou, inversamente, instituem um dever de efetivação do estado de coisas pela adoção de comportamentos a ele necessários".

Nada mais é a boa-fé do que o comportamento aceitado e esperado de todos aqueles que, socialmente convivem e celebram contratos, contraindo obrigações. O comportamento de quem age de boa-fé é aquele tido como legítimo e moralmente aceito.

A boa-fé consiste em princípio diretor de toda e qualquer atividade jurídica, seja no plano material ou processual. Por este motivo, independentemente de qualquer análise quanto à sua natureza ou modalidades, a boa-fé deve ser considerada como um dado implícito no sistema, um princípio generalíssimo. Ou seja: presume-se que todo sujeito inserido numa relação jurídica qualquer se apresente de boa-fé. Este dado é um verdadeiro postulado. Como consequência, cabe àquele que alega a má-fé, o ônus da prova. (Araújo, 2016, p. 183).

Isso faz com que tal princípio exerça forte influência na solução de conflitos, circunstância observada por Cahali (1999, p. 50):

Conforme escreve Alvino Lima, a sua influência na disciplina e solução dos conflitos de interesse é quase sempre decisiva, no sentido de proteger os que agem lealmente, com probidade, ou na ignorância escusável das situações antijurídicas; em sentido contrário, a lei repele as pretensões dos que agem de má-fé, impondo-lhes penalidades restringindo-lhes as faculdades e poderes, ou proclamando a nulidade a anulação ou a ineficácia dos seus atos jurídicos; o princípio da boa-fé constitui, pois, a regra fundamental das relações humanas, quer na constituição das obrigações, como na sua execução, que na confecção dos atos jurídicos, como de um modo geral, em quaisquer atos que possam atingir os interesses de terceiros.

A partir daí, entende-se o porquê da afirmação de que a fraude, participando da má-fé, nega a boa-fé (Cahali, 1999), afinal, condutas eivadas e pertencentes à boa-fé não visam prejudicar ou causar dano a outrem; e, essa intenção maligna, é o que se observa nas situações de fraude.

Para Venosa (2013, p. 459) "fraude é um vício de muitas faces" e "sua compreensão mais acessível é a de todo artifício malicioso que uma pessoa emprega com intenção de transgredir o Direito ou prejudicar interesses de terceiro".

Acrescendo ao conceito estabelecido pelo Professor Silvio de Salvo Venosa, o Professor Washington de Barros Monteiro nos mostra a necessidade de haja, efetivamente, a lesão em decorrência da prática de ato fraudulento, para que se caracterize a fraude propriamente dita (Monteiro, 2009, p. 245). 
A fraude, portanto, caracteriza-se pela má-fé do devedor que num estado de insolvência ou na iminência de se tornar, dispõe de seu patrimônio, de forma gratuita ou onerosa, visando impedir que seus bens respondam por suas obrigações assumidas em momento anterior ao ato de alienação ou oneração de bens.

Em uma simples frase, Pontes de Miranda (2000, p. 490) define que "fraude é o contrário a direito, indiretamente".

Partindo destes conceitos, conclui-se que a fraude traz consigo o sentido de engano, de modo a comportar-se de forma fraudulenta ao cumprimento das obrigações, ou visando prejuízo de terceiros. Isso faz com a que, agir mediante fraude, traga consigo a responsabilidade inerente à pratica de um ato lesivo.

Volta a dizer, Venosa (2013, p. 460):

Não resta dúvida de que fraude a terceiro também é forma de fraude à lei, dentro de conceito amplo.

A regra de direito, ou simplesmente, o Direito, é imperativo disciplinador da sociedade e obriga seus membros a agirem conforme normas. São multiformes os meios e processos empregados pelos infratores para se furtarem ao império e às sanções das leis.

Não ingressam no conceito de fraude aquelas ações ofensivas às normas de forma aberta, flagrante. A fraude caracteriza-se por meios que iludem a lei por via indireta, sem que ocorra forma ostensiva. A fraude da ideia de disfarce, sem adentrar no conceito de simulação.

A fraude orienta-se em direção à finalidade do ato ou negócio jurídico. Geralmente, o objeto e as condições do ato ou negócio são perfeitos. A causa final do ato é que apresenta vício.

E, com a fraude, nos dizeres de Lucon (2000, p. 131) “em termos bem gerais, pode-se afirmar que, coma fraude, há uma diminuição provocada pelo devedor de seu patrimônio, tornando-o insuficiente para os seus credores".

Compreendido que fraude é conduta intencionalmente ungida de má-fé para causar danos e prejuízos a outrem, no direito pátrio, a fraude se materializa, substancialmente, de duas formas: no que se denomina fraude contra credores e na fraude à execução.

A fraude, portanto, é conduta praticada por aquele que, ciente da obrigação assumida, passa a agir no intuído de prejudicar a parte adversa, causando-lhe danos na grande maioria absoluta das vezes. Não tratamos de danos físicos ou psicológicos, mas sim danos materiais decorrentes do não recebimento de valores ou da perda de bens que até então lhe pertencia.

Para que possa haver a pratica da fraude, de atos fraudulentos, faz-se necessário a existência de um negócio jurídico entre partes.

Todo negócio jurídico possui seus requisitos de preenchimento obrigatório para que se tornem válidos no mundo jurídico e possam refletir seus efeitos com relação e em face das partes integrantes das relações negociais celebradas.

Para Degani (2014), “o negócio jurídico visa regular direitos e deveres específicos conforme os interesses dos agentes envolvidos, surgindo um instituto jurídico próprio. Antônio Junqueira de Azevedo brilhantemente afirma que o negócio jurídico constitui o principal exercício da autonomia privada da liberdade negocial. Respeitando sempre os pressupostos de existência, validade e eficácia impostos pela norma jurídica que sobre ele incide."

O negócio jurídico se forma a partir da manifestação de vontade daqueles que desejam contratar, os sujeitos do negócio jurídico, que trazem consigo o objeto da relação negocial prestes a se firmar e a forma com que o negócio será celebrado.

Os pressupostos do plano de validade do negócio jurídico encontram-se expresso pelo artigo 104 do Código Civil, quais sejam: capacidade do agente; objeto lícito possível, determinado ou determinável; e a forma.

Faz-se necessária a exteriorização válida da vontade, por não ser admitida a produção de efeitos relacionada à vontade não exteriorizada; a capacidade do agente, uma vez que a vontade exteriorizada, para produzir efeitos, deve ter sido por quem tenha capacidade e aptidão para a prática dos atos jurídicos; legitimidade do agente, uma vez que aquele que celebra negócio 
jurídico só pode, através deste, agir com relação a bens de que tenha legitimidade para tanto; objeto negocial válido, lícito, possível e determinado; e forma legalmente prescrita, ou seja, a celebração do negócio jurídico através das formas estabelecidas em lei.

Considerando que os negócios jurídicos celebrados devem respeitar pressupostos de existência, validade e eficácia impostos pela norma jurídica, tem-se que o desrespeito a esses pressupostos vai diretamente contra a boa-fé esperada nas relações negociais. E, o negócio jurídico celebrado nestas condições deverá ser considerado viciado.

Os vícios que interessam ao estudo são os denominados vícios sociais, pois, é aqui que se identifica a fraude contra credores.

São sociais, em verdade, porque estes vícios embora estejam ligados a questões patrimoniais e geralmente particulares dos indivíduos, quando presentes e frequentes criam uma sensação de insegurança para os agentes economicamente ativos. Vide, por exemplo, dado a esta incerteza os custos relacionados ao crédito bancário, a enorme burocracia e a necessidade de serem pactuadas diversas garantias acessórias aos contratos, às vezes, por mais simples que sejam.

Com a evolução do direito, o que se observou ao longo do tempo foi que a conceituação do termo fraude também evoluiu a ponto de identificar-se como o recurso astuciosamente empregado com o objetivo de provocar danos (Theodoro Junior, 1996, p. 68).

A fraude contra credores pode ser então entendida como sendo a conduta adotada por devedor que, ciente da existência de uma obrigação contratual, e com flagrante intento de não honrar com a obrigação assumida, ardilosamente dilapida seu patrimônio, vindo a causar danos ao credor, uma vez que, mesmo promovida medida executiva cabível, não haverá em nome do devedor, bens penhoráveis que possam vir a garantir e satisfazer o objeto da dívida.

Sobre o tema, Venosa (2013, p. 460-461) assevera:

Desde os temos em que o devedor já não respondia com o próprio corpo suas dívidas, a garantia de seus credores passou a residir em seu patrimônio.

Não havendo garantia real, privilegiada, conta o credor exclusivamente com a garantia genérica, proporcionada pelos bens. Trata-se de credor quirografário que apenas possui a garantia comum: o patrimônio do devedor.

Esse patrimônio pode ser depauperado de vários modos pelo próprio devedor para frustrar a garantia, seja pela alienação gratuita ou onerosa dos bens, seja remissão de dívidas, pela renúncia da herança, pelo privilégio concedido a um dos credores e por tantos outros meios capazes de diminuir a garantia do credor. Nessas premissas, vêm em socorro do credor as armas conferidas pelas disposições da fraude contra credores (arts. 158 a 165) para recompor o patrimônio do devedor.

A materialização deste atentado contra os credores em decorrência da dilapidação de patrimônio pelo devedor, por uma única razão, no ordenamento jurídico pátrio, é incontestável a responsabilidade patrimonial do devedor, até o limite da obrigação assumida.

Sobre a dilapidação patrimonial, expõe Dinamarco (1993, p. 262-263) que "consiste basicamente na diminuição patrimonial provocada pelo devedor, de modo que em virtude dela o seu ativo passe a ser menor que o passivo. A situação econômica de insolvência consiste precisamente disso, que o patrimônio do devedor, do qual se espera a garantia geral para os seus credores, fica insuficiente e não garante."

E, neste caso, a dilapidação ou alienação patrimonial dar-se-á antes da propositura de um processo executivo, ou, ainda que proposto, antes do recebimento da citação.

Mas, como ocorre a fraude contra credores? Como se opera essa diminuição patrimonial de forma fraudulenta? O devedor consegue, sozinho, praticar atos de fraude contra credores?

Nos dizeres de Didier (2012, p. 303), o desfalque patrimonial mediante fraude contra credores por ocorrer: (a) com a doação de bens para seu filho, (b) com a sua venda a preço vil e simbólico para um "testa-de-ferro", (c) com pagamento de 
dívida não-vencida para credor quirografário (Código Civil, art. 162), (d) com a concessão de uma garantia para um dos credores, onerando bens que serviriam de garantia para todos (CC, art. 163), (e) com renúncia a herança ou outros direitos impedindo o incremento do seu ativo, ou (f) qualquer outro negócio que possa criar com objetivo semelhante.

A partir desses exemplos, é possível observar que o ato fraudulento pode ser: unilateral (exemplo: a renuncia à herança) ou bilateral (exemplo: venda fraudulenta); oneroso (exemplo: compra e venda) ou gratuito (exemplos: doação ou remissão de dívidas).

Entretanto, não é pela simples ocorrência destes fatos que, por si só, esteja configurada a fraude contra credores, é necessário que a conduta adotada atenda a dois pressupostos, conforme continua lecionando Didier (2012, p. 303), sendo um de ordem objetiva e outro de ordem subjetiva. Como pressuposto de ordem objetiva tem-se a exigência de redução patrimonial que conduza o devedor à insolvência, que nada mais é do que a insuficiência patrimonial, motivo pelo qual se materializa o dano (eventos domni), cujo resultado das dívidas superam a importância dos bens do devedor (art. 748, CC).

Ou seja, com a prática de condutas que tendo por objetivo o desfalque patrimonial (dano, enquanto pressuposto objetivo), conseguem dilapidar o patrimônio do devedor (interesse do devedor em causar dano, enquanto pressuposto subjetivo), a ponto de não haverem bens que possam garantir e satisfazer débito contraído com outrem, ora credor, mas que ainda não foi levado à cobrança pelos meios judiciais, tem-se por operada a fraude contra credores.

Impende reforço a esse conceito, com a clara colocação de Salamacha (2006), de que "a fraude contra credores, também chamada de fraude pauliana, ocorre quando há a frustração do princípio da responsabilidade patrimonial, segundo o qual são os bens do devedor que respondem por suas dívidas”.

Com o reconhecimento de que operada a fraude contra credores, tem-se que o ato praticado em flagrante má-fé deve ser declarado nulo, uma vez que se praticados com intento de prejudicar o credor, os atos são anuláveis, por própria previsão legislativa.

Praticada e descoberta o ato em fraude, esse torna-se anulável a pedido do prejudicado e, uma vez declarado nulo, há o retorno das coisas ao estado anterior, permitindo que o patrimônio omitido seja atingido para satisfação de obrigação de pagar quantia certa não adimplida a tempo pelo devedor.

Em contrapartida, se a fraude contra credores está ligado á prática ardilosa de dilapidação patrimonial com o objetivo de fraudar o cumprimento de uma obrigação assumida, sem que haja processo pendente, causando danos apenas ao credor que ficará sem receber aquilo que tem direito e não vislumbrará patrimônio do devedor para garantir e satisfazer o débito, tem-se que a fraude à execução é vislumbrada quando já existente ação com o objetivo de satisfazer o débito inadimplido, tratando-se de remédio processual, instituído para recuperar e trazer para a execução patrimônio que não mais pertença ao devedor.

Marinoni, Arenhart e Mitidiero (2020) assentam que a fraude à execução possui previsão legal no artigo 792 do CPC/2015, se caracterizando como instituto de direito processual, que não onera somente o credor, mas também desfalca o exercício da tutela jurisdicional, uma vez que a satisfação das obrigações que se tornam demandas junto ao Poder Judiciário é, também, de sobremaneira, interessante ao exercício da tutela jurisdicional, uma vez que se o credor não consegue satisfazer a obrigação, permite-se concluir pela ineficiência da outorga jurisdicional prestada.

É conhecido que o ato praticado em fraude contra credores é anulável, e que descoberta e provada a fraude, esse ato se torna nulo, retornando o patrimônio desviado ao devedor, possibilitando seja atingido para fins de satisfação de dívida inadimplida ao tempo certo.

Fala-se em fraude à execução como sendo a conduta adotada de modo a alienar ou onerar bens do devedor, quando o objeto do litigio for o próprio bem, ou quando houver demanda em curso, em face do devedor, cujo resultado seja capaz de reduzi-lo à insolvência (Villar, 2015). 
Para Didier (2012, p. 309) “a fraude à execução é manobra do devedor que causa dano não apenas ao credor (como na fraude pauliana), mas também à atividade jurisdicional executiva. Trata-se de instituto tipicamente processual".

Didier (2012) ainda afirma que, para alguns, a fraude à execução nada mais é do que fraude contra credores qualificada, ou seja, uma especialização ou um aspecto do que se conhece como sendo fraude contra credores. Ou seja, a primeira vista, existe uma similitude, se tratam de institutos diferentes, de modo que Cahali (1999, p. 80) se posiciona de forma objetiva sobre a similitude da fraude contra credores em face da fraude à execução, que também possuem características peculiares e inconfundíveis de cada instituto, destacando se tratarem de institutos distintos, ao dizer que "embora os menos avisados se deslumbrem na demonstração do óbvio, isto é, de que se trata de institutos de características inconfundíveis, mostra-se incontestável que, ontológica e historicamente, a fraude à execução representa um aspecto da fraude contra credores."

Com isso, o autor estabeleceu que “o instituto da fraude à execução constitui uma 'especialização' da fraude contra credores" (Cahali, 1999, p. 80). A doutrina de Didier e Cahali concordam com a similitude da fraude à execução com a fraude contra credores, em decorrência os princípios que regem ambos os institutos.

Em casos onde se configura a fraude à execução, o devedor possui plena ciência da pendência de um processo contra si, mas insiste na condução de práticas cujo único objetivo é dilapidar e camuflar seu patrimônio, tornando-se insolvente a ponto de impossibilitar o recebimento pelo credor, e causando descrédito do Poder Judiciário ao desdenhar da sua capacidade de auxiliar e promover a quitação de dívidas perseguidas judicialmente.

Todavia, ainda que guardem similitudes em decorrência dos princípios que regem, tanto a fraude contra credores, quanto a fraude à execução, "insta não confundir a fraude contra credores com a fraude à execução. Este é instituto de direito processual; aquele, de direito material”. (Paes, 1993).

Prevista no artigo 593 do Código de Processo Civil de 1973 (revogado), a fraude à execução foi trazida para o Novo Código de Processo Civil, alocada no artigo 792, tendo sido ampliada e aperfeiçoada a sua redação. (Villar, 2015).

Cogitar fraude à execução pressupõe a existência de uma ação judicial em face do devedor que, ciente da sua existência, age com o objetivo de ocultar patrimônio para frustrar o resultado útil do processo.

A hipótese do inciso IV do artigo 792 do CPC/2015 também é motivo para configuração de fraude à execução, por ser “o que se configura quando da alienação ou oneração do bem se dá quando 'tramitava contra o devedor ação capaz de reduzi-lo à insolvência"”. (Cãmara, 2017). Ou seja, a fraude à execução opera quando já em curso uma ação judicial em face do devedor.

Uma vez que o art. 792 do $\mathrm{CPC} / 2015^{1}$ trouxe a redação do revogado art. 593 do CPC/73, não há porque não concordar que tal entendimento permanece válido até os dias atuais. Até porque, nos dizeres de Humberto Theodoro Junior (2007, p. 171), "não existe fraude de execução na eminência do processo. Antes de ser instaurada a relação processual, seja condenatória, seja executória, a fraude é apenas contra credores".

\footnotetext{
${ }^{1}$ Art. 792. A alienação ou a oneração de bem é considerada fraude à execução: I - quando sobre o bem pender ação fundada em direito real ou com pretensão reipersecutória, desde que a pendência do processo tenha sido averbada no respectivo registro público, se houver; II - quando tiver sido averbada, no registro do bem, a pendência do processo de execução, na forma do art. 828 ; III - quando tiver sido averbado, no registro do bem, hipoteca judiciária ou outro ato de constrição judicial originário do processo onde foi arguida a fraude; IV - quando, ao tempo da alienação ou da oneração, tramitava contra o devedor ação capaz de reduzi-lo à insolvência; V - nos demais casos expressos em lei. $\S 1^{\circ} \mathrm{A}$ alienação em fraude à execução é ineficaz em relação ao exequente. $\S 2^{\circ}$ No caso de aquisição de bem não sujeito a registro, o terceiro adquirente tem o ônus de provar que adotou as cautelas necessárias para a aquisição, mediante a exibição das certidões pertinentes, obtidas no domicílio do vendedor e no local onde se encontra o bem. $\S 3^{\circ}$ Nos casos de desconsideração da personalidade jurídica, a fraude à execução verifica-se a partir da citação da parte cuja personalidade se pretende desconsiderar. $\S 4^{\circ}$ Antes de declarar a fraude à execução, o juiz deverá intimar o terceiro adquirente, que, se quiser, poderá opor embargos de terceiro, no prazo de 15 (quinze) dias.
} 
O legislador, portanto, buscou dar ao credor instrumentos de efetiva proteção do seu direito ao recebimento daquilo que lhe é devido, ao mesmo tempo que possibilitou a interferência do Estado no processo para prevenir as consequências maiores da fraude, ou seja, que o credor ao se esvaziar patrimonialmente, atende contra a dignidade da justiça, impedindo a prestação jurisdicional devida. (Dutra, 2015).

O instituto, portanto, busca proporcionar o oferecimento de uma tutela jurisdicional plena e favorável à satisfação do direito perseguido pelo credor; mas também, contanto com instrumentos hábeis a desbaratar tentativas de esvaziamento patrimonial pelo devedor, inclusive, sob o risco de responder criminalmente, como forma de frustrar tanto o credor, quanto a própria prestação jurisdicional.

Mais recente posicionamento do Egrégio Superior Tribunal de Justiça, dentro da vigência da atual legislação processual, nos proporciona um exemplo do reconhecimento da fraude a execução no judiciário pátrio, através daquilo que foi dito pela relatora Ministra Nancy Andrighi, no REsp 956.943/PR, julgado em 20/08/2014, apontando que “na alienação de imóveis em fraude de execução deve subsistir a presunção relativa de má-fé do terceiro adquirente, salvo se houver registro da penhora na matrícula do bem, hipótese em que tal presunção será absoluta.”

E, em se tratando de fraude contra credores e fraude à execução, situações que, obviamente, serão submetidos à tutela jurisdicional em caso de inadimplemento, quem são os devidos responsáveis pelo pagamento daquilo que será cobrado.

Por isso, e diante da nítida intenção patrimonial para garantia e recebimento da obrigação, passa-se a analisar as responsabilidades patrimoniais.

\section{Considerações Finais}

É por conclusão, no direito brasileiro, que as relações entre credores e devedores se mostram um tanto quanto envoltas de práticas ardilosas quando o devedor que assumiu uma obrigação toma atitudes no sentido de não honrar com a obrigação assumida, agindo em nítida má-fé.

Se a obrigação assumida estiver sendo obstaculizada antes mesmo do vencimento, ou seja, quando o devedor com a consciente intenção de não adimplir com a obrigação assumida, passa a se desfazer ou promover a ocultação de seu patrimônio, tem-se a prática flagrante de fraude contra credores, que consiste, por não se estar, ainda, no amago do processo, fraude no direito material.

Em contrapartida, quando há existência de processo executivo no sentido de buscar a satisfação de uma obrigação não adimplida no momento do seu vencimento, e se denota a dilapidação patrimonial, configura-se a fraude à execução, consistente em fraude processual, cujo reconhecimento busca agir como forma de reverter a alienação de bens, tornando-o ao patrimônio do devedor, para que possa ser atingido para satisfação da obrigação inadimplida.

Importante tal distinção, uma vez que a depender da modalidade de fraude configurada, buscar-se-á medidas específicas para barrar o desfazimento patrimonial e a garantia de satisfação da obrigação assumida.

\section{Referências}

Araújo, F. C. (2016) Curso de processo civil: parte geral - Atualizado com a Lei 13.256/2016. - São Paulo: Malheiros.

Ávila, H. (2015) Teoria dos princípios: da definição à aplicação dos princípios jurídicos. - 16. ed. rev. e atual. - São Paulo: Malheiros.

Cahali, Y. S. (1999) Fraude contra credores: fraude contra credores, fraude à execução, ação revocatória falencial, fraude à execução fiscal e fraude à execução penal. - 2. ed. rev., e ampl. - São Paulo: Editora Revista dos Tribunais.

Câmara, A. F. (2017) O novo processo civil brasileiro. 3. ed. - São Paulo: Atlas. 
Degani, P. M. (2014) O plano da existência, validade e eficácia do negócio jurídico; os defeitos do negócio jurídico; prescrição e decadência. Jus, 2014. https://jus.com.br/artigos/32132/o-plano-da-existencia-validade-e-eficacia-do-negocio-juridico-os-defeitos-do-negocio-juridico-prescricao-e-decadencia.

Didier Júnior, F.; Braga, P. S.; Oliveira, R. (2012) Curso de Direito Processual Civil. 4. ed. Salvador: Jus Podivm.

Dinamarco, C. R. (1993) Execução Civil. 3. ed. ampl. e atual. São Paulo - Malheiros.

Dutra, F. A. (2015) Fraude de execução e efetividade da prestação jurisdicional. Revista Síntese de Direito Civil e Processual Civil, ISSN 2179-166X, São Paulo, n 96 , jul-ago.

Lucon, P. H. S. (2000) Fraude à Execução, Responsabilidade Processual Civil e Registro de Penhora. Revista Síntese de Direito Civil e Processual Civil, v.1, n. 5 .

Marinoni, L. G.; Arenhart, S. C \& Mitidiero. (2020) Curso de processo civil.

Martins-Costa, J. (2000) A boa-fé no direito privado: sistema e tópica no processo obrigacional. 1 ed. 2. tir. São Paulo: Editora RT.

Miranda, P. (2000) Tratado de direito privado. Campinas: Bookseller.

Paes, P. R. T. (1993) Fraude contra credores. 3. ed. aum. e. atual. - São Paulo: Editora Revista dos Tribunais.

Pedrosa, M. (2013) Princípio da boa-fé. Jusbrasil, 2013. https://marcospedrosapedrosa.jusbrasil.com.br/artigos/111813775/principio-da-boa-fe.

Salamancha, J. E. (2006) Fraude contra credores: efeitos da sentença na ação pauliana. Revista de Processo, vol. 135/2006, p. 75-89, mai. 2006. https://www.revistadostribunais.com.br/maf/app/widgetshomepage/resultList/document?\&src=rl\&srguid=i0ad82d9b0000017e70e0f57c1a5a9ce5\&docguid=Ib e10de50f25611dfab6f010000000000\&hitguid=Ibe10de50f25611dfab6f010000000000\&spos=1\&epos=1\&td=2101\&context=185\&crumbaction=append\&crumb-label=Documento\&isDocFG=false\&isFromMultiSumm=\&startChunk=1\&endChunk=1 .

Theodoro Junior, H. (1996) Fraude contra credores: a natureza da sentença pauliana. - Belo Horizonte: Del Rey.

Theodoro Junior, H. (2007). Processo de execução e cumprimento de sentença. 24. ed. rev., ampl. e atual. - São Paulo: Liv. e Ed. Universitária de Direito.

Venosa, S. S. (2013) Direito civil: parte geral. 13. ed. - São Paulo: Atlas.

Villar, A. S. (2015) O reconhecimento da fraude à execução no novo CPC. Jusbrasil, 2015. https://alice.jusbrasil.com.br/artigos/235904899/oreconhecimento-da-fraude-a-execucao-no-novo-cpc. 